\title{
Juvenile Muscular Atrophy of the Proximal Upper Extremity as So-Called Proximal-Type Hirayama Disease: Case Report and Review of the Literature
}

\author{
Akira Yokote Kousuke Fukuhara Jun Tsugawa Yoshio Tsuboi \\ Department of Neurology, Fukuoka University School of Medicine, Fukuoka, Japan
}

\section{Keywords}

Juvenile muscular atrophy $\cdot$ Hirayama disease $\cdot$ MRI $\cdot$ Proximal muscles

\begin{abstract}
Hirayama disease is a distinct type of cervical myelopathy characterized by juvenile onset of unilateral muscular atrophy of a distal upper extremity. We report herein a case with Hirayama disease-like juvenile muscular atrophy involving proximal muscles in the upper extremities. In this case, in the flexion position of the neck, cervical magnetic resonance imaging revealed that the spinal cord was compressed by expansion of the posterior extradural space with forward displacement of the dura matter. These neuroimaging results are identical to those of Hirayama disease. However, the involved muscles in this case were the proximal muscles, unlike Hirayama disease. Five previous cases have displayed this rare subtype of Hirayama disease. The cause of the unique phenotype may be abnormal cervical column alignment, with upper cervical kyphosis producing a higher apex of the vertebral level in a cervical flexion position, resulting in mid-cervical segmental myelopathy.

(C) 2019 The Author(s)

Published by S. Karger AG, Basel
\end{abstract}




\section{Case Reports in Neurology}

Case Rep Neurol 2019;11:106-111

DOI: $10.1159 / 000495606$

(C) 2019 The Author(s). Published by S. Karger AG, Base www.karger.com/crn

Yokote et al.: Proximal-Type Hirayama Disease

\section{Introduction}

Juvenile muscular atrophy of distal upper extremity (Hirayama disease) is a rare neurological disease affecting mainly male adolescents [1]. Hirayama disease is characterized by isolated weakness and muscular atrophy in the hand and forearm, usually either unilateral or asymmetrically bilateral. Neuroradiological findings in Hirayama disease uniformly reveal cervical cord compression by expansion of the posterior extradural space with forward displacement of the spinal cord at neck flexion position. This may be caused by congestion of the dilated venous plexus in the posterior epidural space [2,3]. Hirayama disease displays a signature muscular atrophy pattern (so-called oblique atrophy) of the unilateral upper limb, but the reasons for the localization to one side and the distal distribution are unknown. Here, we report a case of male adolescent presenting with muscular atrophy in the proximal upper extremities. Neuroimaging showed expansion of the posterior epidural space with forward displacement at neck flexion posture, as in Hirayama disease. We describe the symptoms, characteristic images, treatment, and clinical course of this case.

\section{Case Presentation}

The patient was an 18-year-old man with a history of atopic dermatitis and rhinitis since a young age. He had shown normal development without any other comorbidities. His sister also had atopic dermatitis. Until May 20XX, he belonged to the track team as a middle-distance runner. He was aware of difficulty with raising both arms when changing clothes. In addition, he experienced difficulty lifting heavy bags. Weakness in both arms gradually progressed over the course of 3 months, and he was admitted to our hospital on August 20XX. Neurological examination revealed muscular weakness and atrophy in the deltoid, infraspinatus, supraspinatus, and biceps brachii bilaterally, but predominantly affecting the right side. He was alert and cranial nerves were intact. His sensory system revealed no abnormalities. Tendon reflexes were mildly decreased in the biceps and brachioradialis, with preserved triceps reflex. Cerebellar function and gait were normal.

Complete blood counts, blood chemistry, and urinalysis revealed normal results. Nerve conduction studies were normal. Electromyography showed chronic denervation in bilateral biceps brachii muscle, but normal results in bilateral first dorsal interosseous muscles.

On sagittal T1 and T2-weighted cervical MRI in the neutral position, marked atrophy of the spinal cord was evident and the curve of the cervical was kyphotic at the C4-C6 vertebral level (Fig. 1a). The apex of the cervical kyphosis was located at the C4/C5 vertebral level. Axial T2-weighted MRI showed a flattened spinal cord and intramedullary signal hyperintensity on the right side (Fig. 1b). Sagittal T2-weighted cervical MRI in the flexion position showed expansion of the posterior extradural space and forward displacement of the spinal cord at the C3-C6 vertebral level (Fig. 1c). Axial T2-weighted MRI showed hyperintensity of the posterior extradural space at the C4-C5 vertebral levels. Gadolinium-enhanced T1-weighted MRI with flexion position showed homogeneous enhancement of the posterior extradural space at the C3-C6 vertebral levels (Fig. 1d). Cervical myelography in a flexed position showed cervical cord atrophy at the C4-C5 vertebral levels with a narrowed dural canal and forward displacement of the cervical cord at the C4-C6 vertebral levels (Fig. 2). 


\section{Case Reports in Neurology}

We provided guidance in avoiding neck flexion exercises and wearing a neck collar, and have conducted follow-up examinations without operation. After 12 months, his symptoms were stable with some mild improvement.

\section{Discussion}

Our case presented with muscular weakness and atrophy in the proximal arms bilaterally at the C5-C6 myotome level. Cervical T2-weighted MRI showed spinal cord atrophy and intramedullary hyperintensity at the C4-C6 vertebral levels. In the flexion position of the neck, the dura mater shifted forward with an enlarged posterior epidural space, including homogeneous gadolinium enhancement of the epidural space, revealing engorgement of the posterior internal vertebral venous plexus and stasis of blood flow, as typically seen in previous reports of Hirayama disease [2, 3]. Although neuroradiological findings were consistent with Hirayama disease, the involvement of muscular atrophy was unusual.

Similar cases have been described, showing juvenile muscular atrophy of the proximal upper extremities caused by a pathogenesis similar to Hirayama disease. To the best of our knowledge, six such cases have been reported, including the present patient [4-8]. These cases with "proximal-type Hirayama disease" were characterized by spinal cord involvement at the C4-C6 vertebral level in young men, mostly with good prognosis (Table 1). In addition, we speculated that the unique phenotype was attributable to the C4-C5 spinal column alignment of "upper cervical kyphosis" in these cases. Upper cervical kyphosis may produce a relatively higher level involvement of the spinal cord at cervical flexion position, resulting in midcervical segmental myelopathy.

In general, use of a cervical collar is recommend to avoid neck flexion. Several reports have described the usefulness of surgical therapy with cervical spinal fusion [9]. We successfully treated our case by adequate guidance on refraining from neck flexion exercises and wearing a neck collar. Early use of a neck collar may offer good prognosis, as in proximal-type Hirayama disease.

\section{Conclusion}

According to our case and previous reports, a subtype of Hirayama disease presents with proximal involvement of the upper extremities. The pathomechanism of proximal involvement is speculated to be due to an unusual spinal column alignment as so-called "upper cervical kyphosis," involving a difference in the apex vertebral level in cervical flexion, resulting in symptoms different from typical Hirayama disease.

\section{Statement of Ethics}

The patient provided oral informed consent for publication of this report. 


\section{Disclosure Statement}

The authors have no conflicts of interest to disclose.

\section{Funding Sources}

This study did not receive any external funding.

\section{Author Contributions}

Akira Yokote wrote the initial draft of the manuscript and reviewed the literature. Kousuke Fukuhara was the primary physician for the patient. Jun Tsugawa helped refine the manuscript. Yoshio Tsuboi was involved in the planning and guidance of the written manuscript. All authors were equally involved in the medical management of the patient and approved the final version of the manuscript.

\section{References}

1 Hirayama K. Juvenile muscular atrophy of distal upper extremity (Hirayama disease). Intern Med. 2000 Apr;39(4):283-90.

2 Chen CJ, Chen CM, Wu CL, Ro LS, Chen ST, Lee TH. Hirayama disease: MR diagnosis. AJNR Am J Neuroradiol. 1998 Feb;19(2):365-8.

3 Baba Y, Nakajima M, Utsunomiya H, Tsuboi Y, Fujiki F, Kusuhara T, et al. Magnetic resonance imaging of thoracic epidural venous dilation in Hirayama disease. Neurology. 2004 Apr;62(8):1426-8.

4 Masaki T, Hashida H, Sakuta M, Kunogi J. [A case of flexion myelopathy presenting juvenile segmental muscular atrophy of upper extremities - a successful treatment by cervical spine immobilization] [in Japanese, abstract in English]. Rinsho Shinkeigaku. 1990 Jun;30(6):625-9.

5 Ando T, Fukatsu H, Kameyama T, Takahashi A, Yamada H. [A case of flexion myelopathy presenting with reversible muscular weakness and atrophy of the unilateral proximal upper limb] [in Japanese, abstract in English]. Rinsho Shinkeigaku. 1993 May;33(5):575-8.

6 Yaguchi H, Takahashi I, Tashiro J, Tsuji S, Yabe I, Sasaki H. Scapular winging as a symptom of cervical flexion myelopathy. Intern Med. 2007;46(8):511-3.

7 Jung HJ, Nam TS, Choi SM, Lee SH, Kim BC, Kim MK. Hirayama disease presenting as isolated triceps atrophy. J Clin Neurosci. 2013 Oct;20(10):1450-1.

8 Paeng SH, Kim YJ, Oh S, et al. Predominant proximal upper extremity involvement in Hirayama disease. Neurol Asia. 2015;20(3):301-3.

9 Kohno M, Takahashi H, Ide K, Yamakawa K, Saitoh T, Inoue K. Surgical treatment for patients with cervical flexion myelopathy. J Neurosurg. 1999 Jul;91(1 Suppl):33-42. 


\section{Case Reports in Neurology}

Case Rep Neurol 2019;11:106-111

DOI: $10.1159 / 000495606$

(C) 2019 The Author(s). Published by S. Karger AG, Basel www.karger.com/crn
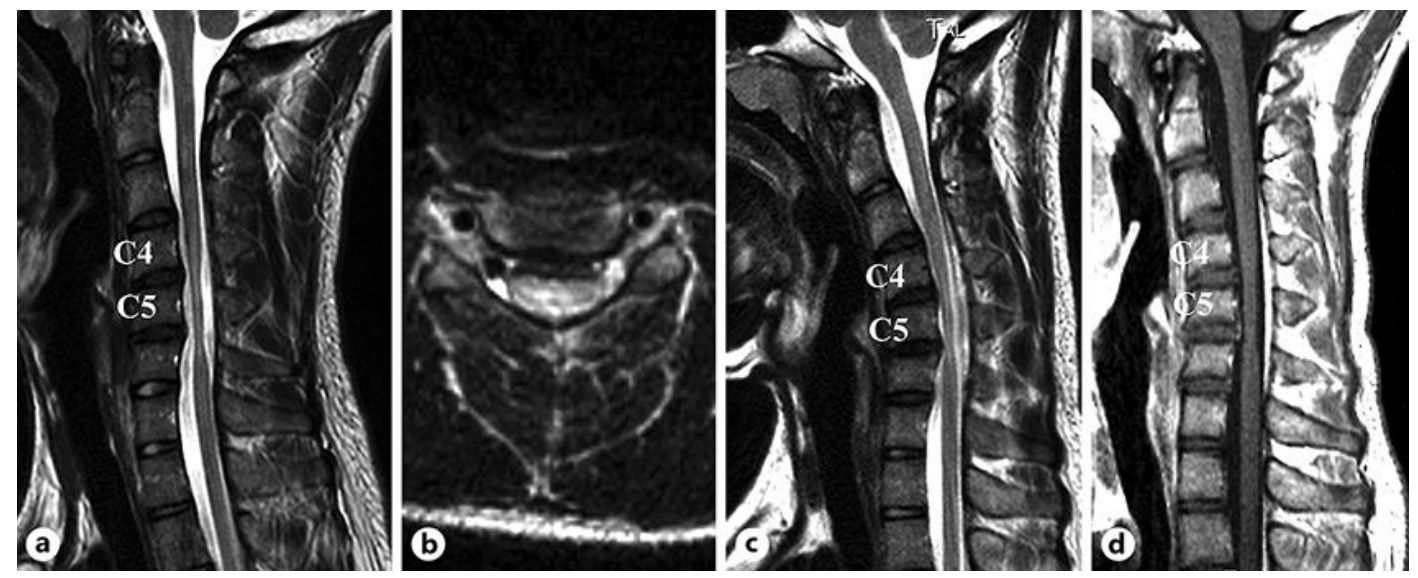

Fig. 1. a Sagittal T2-weighted cervical MRI in neutral position shows marked spinal cord atrophy at the C4-C6 vertebral level. b Axial T2-weighted cervical MRI in neutral position shows hyperintensity of the right-sided intramedullary and a flattened spinal cord at the C4/C5 vertebral level. c Sagittal T2-weighted cervical MRI in flexion position shows expansion of the posterior extradural space and forward displacement of the spinal cord at the C3-C6 vertebral level. $\mathbf{d}$ Gadolinium-enhanced T1-weighted MRI with flexion position showed homogeneous enhancement of the posterior extradural space at the $\mathrm{C} 3-\mathrm{C} 6$ vertebral levels.

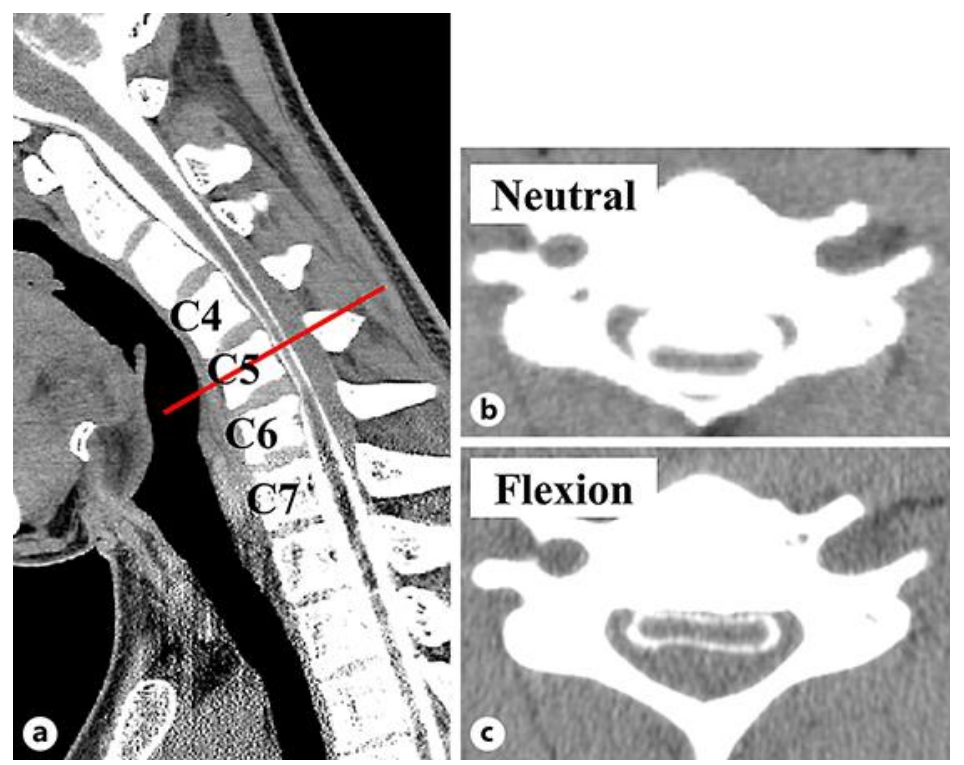

Fig. 2. a Sagittal cervical myelography in flexion position shows marked atrophy of the spinal cord at the C4-C5 vertebral level. b, c Axial cervical myelography in neutral and flexion positions shows flattened spinal cord and forward displacement of the spinal cord at the C4/C5 vertebral level. 
Yokote et al.: Proximal-Type Hirayama Disease

Table 1. Previously reported cases of proximal upper extremity cervical flexion myelopathy

\begin{tabular}{|c|c|c|c|c|c|c|c|}
\hline $\begin{array}{l}\text { First author } \\
\text { [Ref.], year }\end{array}$ & Sex & $\begin{array}{l}\text { Age at on- } \\
\text { set, years }\end{array}$ & $\begin{array}{l}\text { Age at diag- } \\
\text { nosis, years }\end{array}$ & Muscle weakness & $\begin{array}{l}\text { Level of } \\
\text { cervical cord } \\
\text { compression }\end{array}$ & Treatment & Prognosis \\
\hline $\begin{array}{l}\text { Masaki }[4] \text {, } \\
1990\end{array}$ & Male & 18 & 24 & Bilateral deltoid, right biceps brachii & C4/C5 & Operation & Improved \\
\hline $\begin{array}{l}\text { Ando [5], } \\
1993\end{array}$ & Male & 16 & 16 & $\begin{array}{l}\text { Right deltoid, biceps brachii, brachioradi- } \\
\text { alis }\end{array}$ & C4/C5 & Observation & Improved \\
\hline $\begin{array}{l}\text { Yaguchi [6], } \\
2007\end{array}$ & Male & 16 & 23 & Right triceps, serratus anterior & C4/C5 & Observation & $\begin{array}{l}\text { No progres- } \\
\text { sion }\end{array}$ \\
\hline $\begin{array}{l}\text { Jung [7], } \\
2013\end{array}$ & Male & 18 & 19 & Right biceps brachii & C4/C5 & Neck collar & $\begin{array}{l}\text { No progres- } \\
\text { sion }\end{array}$ \\
\hline $\begin{array}{l}\text { Paeng [8], } \\
2015\end{array}$ & Male & 18 & 19 & Right biceps brachii & $\mathrm{C} 4 / \mathrm{C} 5$ & Neck collar & $\begin{array}{l}\text { No progres- } \\
\text { sion }\end{array}$ \\
\hline $\begin{array}{l}\text { This report, } \\
2018\end{array}$ & Male & 18 & 18 & $\begin{array}{l}\text { Bilateral deltoid, supraspinatus, infrasp- } \\
\text { inatus, biceps brachii }\end{array}$ & $\mathrm{C} 4 / \mathrm{C} 5$ & Neck collar & Improved \\
\hline
\end{tabular}

